\title{
Germanica
}

\section{Denis BOUSCH (dir.), Utopie et science-fiction dans le roman de langue allemande}

Paris, L'Harmattan, 2007, 282 p. , $25 €$

\section{Elfie Poulain}

\section{OpenEdition \\ Journals}

Édition électronique

URL : http://journals.openedition.org/germanica/494

DOI : 10.4000/germanica.494

ISSN : 2107-0784

\section{Éditeur}

Université de Lille

\section{Édition imprimée}

Date de publication : 1 décembre 2007

Pagination : 182-183

ISBN : 978-2-913857-20-9

ISSN : 0984-2632

Référence électronique

Elfie Poulain, « Denis BOUSCH (dir.), Utopie et science-fiction dans le roman de langue allemande », Germanica [En ligne], 41 | 2007, mis en ligne le 27 octobre 2009, consulté le 06 octobre 2020. URL : http://journals.openedition.org/germanica/494 ; DOI : https://doi.org/10.4000/germanica.494

Ce document a été généré automatiquement le 6 octobre 2020.

(c) Tous droits réservés 


\title{
Denis BOUSCH (dir.), Utopie et science-fiction dans le roman de langue allemande
}

Paris, L'Harmattan, 2007, 282 p. , $25 €$

\author{
Elfie Poulain
}

\section{RÉFÉRENCE}

Denis BOUSCH (dir.), Utopie et science-fiction dans le roman de langue allemande,Paris, L'Harmattan, 2007, 282 p. , $25 €$.

1 Cet ouvrage, fruit d'un colloque organisé à l'Université de Paris 12 en mai 2002, regroupe 14 articles de spécialistes français, allemands et autrichiens portant sur des auteurs de langue allemande $\mathrm{du} \mathrm{xx}^{\mathrm{e}}$ siècle dont les romans relèvent aussi bien du genre des romans utopiques à connotation philosophique que de la science-fiction, généralement dédiée aux anticipations technologiques, et des romans futuristes qui s'apparentent au thriller politique. L'enchaînement des articles obéit apparemment à un ordre chronologique de la publication des ouvrages analysés.

2 Les trois premiers articles sont à orientation politique. Thomas F. Schneider élabore une typologie de la littérature pacifiste sur la Première Guerre mondiale: il en démontre l'ambiguïté en faisant voir qu'ils sont dotés d'une superstructure idéologique visant la construction d'un nouvel ordre politique. Robert Hahn présente les éléments constitutifs du personnage du chef et examine le rôle de la technique et de la vulgarisation scientifique pour déceler les idées nationalistes dans les romans d'anticipation qui ont promu une démagogie préfasciste. Jost Hermand présente Hans Dominik, auteur célèbre sous le nazisme qui célébra l'idéologie et la supériorité de la race blanche et le danger venant de la race jaune.

3 Suivent trois articles à orientation philosophique. Harro Sebeberg décrit le cheminement des projections futuristes d'Ernst Jünger: l'utopie véritable n'y est pas 
liée à l'évolution que connaît le développement technique ou social, mais vise le retour de l'origine à un échelon supérieur. Béatrice Poulain retrace le sens de l'utopie du roman Le Jeu des Perles de Verre de Hermann Hesse. Elle en décrit la conformité avec les caractéristiques formelles du genre, l'actualisation des mythes et l'héritage de la pensée nietzschéenne et parvient ainsi à démontrer que l'utopie constitue pour Hesse l'unique mode de protestation littéraire contre les puissances barbares. Daniel Meyer analyse le roman futuriste Der Stern der Ungeborenen de Franz Werfel: écrit sur fond de la Divine Comédie de Dante, il présente une conception dialecto-cyclique de l'histoire qui constitue une médiation utopique vers la contemplation divine.

4 Les articles suivants portent sur la littérature futuriste après 1945. Denis Bousch aborde le roman d'anticipation Die Erben des Untergangs de l'écrivain bavarois Oskar Maria Graf, pour décrire les utopies sociales et le contexte d'un monde globalisé après l'apocalypse nucléaire provoquée par une Troisième Guerre mondiale. Joanna Jablkowska reprend cette même thématique et expose trois utopies apocalyptiques de l'après-guerre (Grass, Heym et Drost) où elle dénote le recours à l'esthétisme de l'épouvante. En se fondant sur l'étude interplanétaire intitulée: Le projet Mars, que Werner von Braun rédigea aux États-Unis et le roman Des hommes entre les planètes de Franz Ludwig Neher, Helga Abret décrit la manière dont les inventions techniques, ici l'astronautique, et les fictions littéraires s'inspirent les unes les autres. Hans Esselborn explore les romans antiutopiques de Herbert W. Franke qui décrivent les possibilités et utilisations des mondes virtuels, régis par des ordinateurs, ainsi que leurs terribles conséquences pour l'humanité.

5 Les deux contributions suivantes posent la question de savoir si la science-fiction a existé en RDA. Jens Ebert présente les utopies alarmistes que contient le recueil de nouvelles Saïans Fiktschen de Franz Fühmann, et Hans-Christian Stillmark présente la vie de l'artiste Wieland Föster. Le recueil se clôt par deux contributions sur la littérature utopiques des années 1990. Les interrelations entre les développements biotechnologiques, génétiques, et les fictions bioscientifiques des auteurs Simmel, Ch. Kerner et et $\mathrm{G}$. Grass constituent le thème de la contribution de Rudolf Drux. Elisabeth Rothmund nous livre deux visions alternatives sur la division et la réunification de l'Allemagne, celle de l'écrivain Th. Becker et celle de l'historien Chr. von Ditfurth qui jouent avec le rapport entre réalité et illusion, utopie et cauchemar.

6 L'ensemble des articles offre une introduction intéressante et bien documentée sur la complexité de la littérature futuriste de langue allemande, peu ou mal connue en France. 